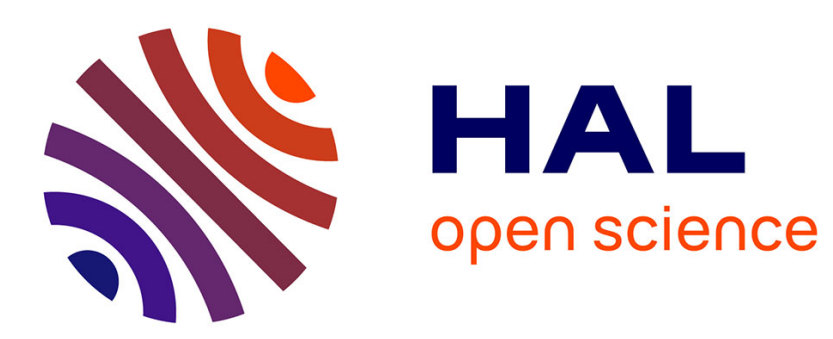

\title{
Are perceived learning environments related to subjective well-being? A visit to university students
}

Chen Chen, Jieqiong Fan, Mickaël Jury

\section{To cite this version:}

Chen Chen, Jieqiong Fan, Mickaël Jury. Are perceived learning environments related to subjective well-being? A visit to university students. Learning and Individual Differences, 2017, 54, pp.226 233. 10.1016/j.lindif.2017.01.001 . hal-01859636

\section{HAL Id: hal-01859636 https://hal.science/hal-01859636}

Submitted on 8 Nov 2019

HAL is a multi-disciplinary open access archive for the deposit and dissemination of scientific research documents, whether they are published or not. The documents may come from teaching and research institutions in France or abroad, or from public or private research centers.
L'archive ouverte pluridisciplinaire HAL, est destinée au dépôt et à la diffusion de documents scientifiques de niveau recherche, publiés ou non, émanant des établissements d'enseignement et de recherche français ou étrangers, des laboratoires publics ou privés. 


\title{
Are perceived learning environments related to subjective well-being? A visit to university students ${ }^{1}$
}

Chen Chen ${ }^{\text {a,b }}$, , Jieqiong Fan , Mickaël Jury ${ }^{\mathrm{d}}$

a School of Psychology, Nanjing Normal University, Chin

$\mathrm{b}$ Research Institute of Moral Education, Nanjing Normal University, China

c Faculty of Education, East China Normal University, China

d ESPELilleNorddeFranceandEA4072-PSITEC-Psychologie: Interactions, Temps, Émotions, Cognition, F59000 Lille, France

\begin{abstract}
This study examined whether university students' subjective well-being is linked to their perception of learning environments grounded in constructivism. Five hundred and twelve students from two universities in China participated in the study. The participants completed questionnaires in class concerning the extent to which they perceived their learning environment to be constructivist-oriented and their subjective well-being (i.e., life satisfaction and positive and negative affect). After controlling for demographic variables (i.e., age, sex, university, and major), students' perceptions of a constructivist learning environment were significantly linked to their life satisfaction and positive and negative affect. More specifically, the environmental dimensions of clear goals and coherence of curricula, student-student cooperation, and learning facilities were positively associated with life satisfaction, and clear goals and coherence of curricula and learning facilities were also positively related to positive affect. However, student autonomy was found to be negatively related to life satisfaction. Despite that these results are correlational in nature, implications for higher education are discussed.
\end{abstract}

Keywords: Learning environment Constructivism Subjective well-being University students

\section{Introduction}

In research on school effectiveness, considerable attention is paid to the influence of learning environments on academic outcomes (e.g., academic performance), but less attention is afforded their influence on non-academic outcomes (Rutter \& Maughan, 2002). Given that educators are increasingly attaching importance to non-academic outcomes as one of the aims of education (Noddings, 2005), it is necessary to identify the characteristics of learning environments that are linked to students' social and emotional outcomes such as subjective wellbeing (SWB).

Several researchers have examined the relationships between learning environments grounded in or consistent with constructivism and students' mental health and/or satisfaction with the classroom and school life (Dyrbye et al., 2009; Kangas, 2010; Loyens, Rikers, \& Schmidt, 2007; Maton, 1990; Milkie \& Warner, 2011; Shernoff, Csikszentmihalyi, Shneider, \& Shernoff,

\footnotetext{
${ }^{1}$ This paper has been published in Learning and Individual Differences in 2017. This is the post-print version. The full reference is available at the end of the manuscript.

${ }^{2}$ Dr. Chen Chen, Professor in School of Psychology and Adjunct Research Professor in the Research Institute of Moral Education at Nanjing Normal University; Dr. Jieqiong Fan, Lecturer in Faculty of Education, East China Normal University; Dr. Mickaël Jury, Assistant Professor at ESPE Lille Nord de France and EA 4072 PSITEC Psychologie: Interactions, Temps, Émotions, Cognition, F-59000 Lille, France.
} 
2003; So \& Brush, 2008; Tan \& Zeng, 2007), but their investigations have not always been comprehensive and systematic. For example, only a few learning environment dimensions have been examined in relation to SWB (see details in Section 1.2). Moreover, the inventories assessing learning environments consistent with constructivism focus primarily on the classroom rather than school (or university/college) level (Li, Hu, Pan, Qin, \& Fan, 2014). In addition, in the few existing school-level inventories (e.g., Huang \& Fraser, 2009), school environments are assessed from the perspective of teachers rather than students. Therefore, the purpose of the study reported in the present paper was to examine the link between students' perception of a learning environment that describes or reflects the features of constructivism at the university level and their SWB at university by considering a variety of learning environment dimensions inside and outside the classroom.

\section{Theoretical frameworks of learning environments and subjective wellbeing}

\section{Learning environments}

Fraser (1998) described learning environments as "the social, psychological, and pedagogical contexts in which learning occurs and which affect student achievement and attitudes" (p. 3). From the constructivist perspective, learning is regarded as a process of active knowledge construction (Brooks \& Brooks, 1993; Loyens \& Gijbels, 2008; Steffe \& Gale, 1995). As a result, effective learning environments consistent with constructivism (i.e., constructivist learning environments, CLE hereafter) should pay attention to the process of knowledge construction (i.e., encouraging high-quality thinking; De Corte, 1995, 2000) and help students to understand the structure and process of such construction (Moreno \& Mayer, 1999). In addition, an effective CLE should make students responsible for their own learning (Vermunt, 2003) and support interactions and cooperation with teachers and peers to cultivate initiative and proactivity in the learning process (van Merriënboer \& Paas, 2003).

Although the concept of constructivism is relatively popular in the learning environment arena, its influence on student outcomes remains open to debate. Some studies have documented a positive relationship between learning environment (with some constructivist features) and achievement (Harris, Santangelo, \& Graham, 2008; Mason, 2004; Weinberger \& McCombs, 2001). For example, when self-regulated learning is facilitated, achievement is enhanced (Harris et al., 2008; Mason, 2004). Learner-centered pedagogy in the classroom has also been found beneficial to academic performance (Weinberger \& McCombs, 2001). However, other research has failed to detect a positive learning environment-outcome relationship (Dethlefs, 2003; Klein \& Schnackenberg, 2000). Albanese and Mitchell (1993), for example, reviewed studies on problem-based learning (PBL, a feature of a constructivist learning environment) in medical programs and found that, in some, PBL graduates had achieved better performance in clinical examinations and faculty evaluations than their peers who had received traditional training, whereas other studies found no such superiority for PBL (for another illustration of this inconsistency, see Dinsmore, Alexander, \& Loughlin, 2008).

One likely reason for the divergent findings regarding the effectiveness of CLE in previous research might be the use of different student learning outcomes, ranging from subject grades and GPAs to students' grades in a single course, to evaluate such effectiveness (Fan \& Zhang, 2014). Grades and especially GPA are commonly used as the dominant measures of academic performance. However, "their reliability and validity have been questioned because of factors such as grade inflation, which is the tendency to provide higher grades for the same substantive performance at different levels of study or at different periods in time" (Johnson, 1997, cited in Poropat, 2009, p. 323). This problem of the reliability of GPA may affect the measure's temporal stability and its correlations with other variables (Poropat, 2009). In this sense, the 
extent to which grades could represent students' actual ability may also differ. In contrast, in most cases of non-academic outcomes, such as SWB, the same instruments or inventories are often adopted across multiple studies with information regarding reliability and validity being reported, which renders their results more comparable (e.g., Diener, Tay, \& Oishi, 2013; Thompson, 2007). Another problem with the extant literature on CLE effectiveness in relation to academic outcomes is that the learning environments examined are characterized by different aspects of constructivist features in different studies. Accordingly, the differing nature of outcome assessments and different environmental dimensions considered in these studies have led to inconsistent results (Albanese \& Mitchell, 1993; Dethlefs, 2003; J. D. Klein \& Schnackenberg, 2000; Weinberger \& McCombs, 2001). Investigating non-academic outcomes utilizing widely used inventories and considering different CLE dimensions simultaneously may thus help to get a more precise picture of CLE effectiveness. In other words, examining the relationship between CLE and SWB may provide additional insights for the discussion of CLE effectiveness.

\section{Subjective well-being}

SWB has been defined from a range of perspectives using different terms (Diener, 1984). However, the most widely accepted definition is: "a person's cognitive and affective evaluations of his or her life as a whole" (Diener, Oishi, \& Lucas, 2009, p. 187). Thus, SWB includes both cognitive judgments concerning life (i.e., life satisfaction) and emotional reactions to life events (i.e., positive and negative affect).

Previous research suggests that perceptions of well-being derive from the summation of momentary pleasurable experiences and pleasure experienced in different life domains. In other words, life events and circumstances influence judgments of domain satisfaction and emotional experiences, which in turn influence global judgments of well-being. These results seem to support bottom-up theories of SWB (see Diener, Lucas, Oishi, \& Suh, 2002; Paykel, 2003). In line with the purpose of the present study, the literature on learning environmentrelated factors linked to SWB is discussed in the following section.

\section{Relationship between learning environments and subjective well-being}

At the theoretical level, the notions of positive psychology and constructivism give rise to examination of the link between learning environments and SWB. Positive psychology assumes that engagement and meaning are two important indicators of well-being (Cohen, 2006), which accords with the epistemology of constructivism underpinning CLE. From the perspective of constructivism, students play an active role in their own learning, and knowledge should be constructed within an authentic context (Loyens \& Gijbels, 2008). Therefore, learning environments based on constructivism purposefully encourage students to engage themselves in constructing knowledge and to identify meaning through the process of knowledge construction and making connections with real life. As a consequence, the engagement and meaning identification induced by a constructivist-oriented learning environment would be related to students' cognitive and affective experience of well-being.

At the empirical level, the link between CLE and SWB has been examined to a lesser extent than that between SWB and other variables, such as ethnicity, culture, income, familial relationships, marriage, employment, and other life events (e.g., Diener \& Biswas-Diener, 2002; Diener \& Diener McGavran, 2008; Lucas, 2005; Lucas, Clark, Georgellis, \& Diener, 2004; Oishi, 2001; Veenhoven, Ehrhardt, Ho, \& de Vries, 1993). A few studies have demonstrated a relationship between learning environments with certain features of 
constructivism and student problem behavior and mental health (e.g., Dyrbye et al., 2009; Kumar, O'Malley, \& Johnston, 2008; Milkie \& Warner, 2011; Suldo, McMahan, Chappel, \& Loker, 2012). For example, Milkie and Warner (2011) found classrooms with fewer material resources to be associated with children having more learning, externalizing, interpersonal, and internalizing problems. These classrooms had a more negative atmosphere and made it more difficult for teachers and students to use active techniques (e.g., experiments and/or real-world problem solving) to create more knowledge. In the same vein, Dyrbye et al. (2009) conducted a study among medical students, and discovered that such learning environment dimensions as collaborative learning, supervision availability, constructive feedback, and available support from others are significantly related to minimizing student burnout.

Moreover, research has also suggested that learning environments that capture certain features of constructivism are potentially linked to student satisfaction with specific life domains. For example, Tan and Zeng (2007) carried out a survey with high school students to investigate the relationship between certain learning environment dimensions (e.g., the teacher-student relationship, relationships with classmates, and learning burden) and six domains of student satisfaction (i.e., friendship, family, school, academic performance, freedom, and environment). They found the first two dimensions to be positively associated with all of the satisfaction domains, and the third, learning burden, to be negatively related to every satisfaction domain except friendship. Furthermore, researchers have demonstrated perceived teacher support and peer support to be positively related to students' satisfaction with school life (Baker, 1998, 1999; Gest, Welsh, \& Domitrovich, 2005). In addition, satisfaction with courses and satisfaction among students are positively associated with collaborative learning environments (So \& Brush, 2008) and learning environments characterized by meaningful activities that permit student autonomy and engagement (Kangas, 2010; Maton, 1990; Shernoff et al., 2003), respectively.

Although the aforementioned studies suggest a relationship between CLE and student SWB, several limitations need to be noted. First, the CLE dimensions covered by these studies are limited in number. As a result, an incomplete understanding of CLE makes it difficult to identify the CLE characteristics that may be linked to student SWB. Second, previous research has not systematically examined the correlation between CLE dimensions and the cognitive judgment (satisfaction) and emotional reaction (affect) components of SWB. Third, most of the studies cited above were conducted among high school and elementary school students. The association between CLE and SWB in university students has to date received little attention, possibly because of the lack of an appropriate inventory for assessing the general university environment. In fact, the university learning environment probably plays a more important role in student SWB than the school environment because university students are often living far from their families for the first time and engaged in forming a new social identity, which can be particularly tough (Iyer, Jetten, Tsivrikos, Postmes, \& Haslam, 2009).

In this regard, the aim of the current study was to investigate the relationship between perceived CLE and student SWB using a newly designed, comprehensive inventory of a wide range of learning environment dimensions, namely, the Inventory of Students' Perceived Learning Environment (ISPLE), which demonstrated acceptable psychometric properties in a recent study involving Chinese university students (Fan \& Zhang, 2014). It was hypothesized that the more students perceive their general learning environment as constructivist, the higher the SWB levels they will report. This hypothesis was notably based on previous findings showing some dimensions of CLE (e.g., student cooperation and constructive feedback from teachers) to be positively related to mental health and domain satisfaction (Baker, 1998, 1999; Dyrbye et al., 2009; Gest et al., 2005; So \& Brush, 2008). 


\section{Method}

\section{Participants}

Five hundred and twelve students from two universities in East China (172 from a university in Nanjing and 340 from a university in Shanghai) participated in this study. The participants ranged in age from 16 to $23(\mathrm{M}=19.13, \mathrm{SD}=0.89)$, and the majority (352) were women. Most were in their first $(86.33 \%)$ or second $(13.67 \%)$ year of university, and $52.54 \%$ were majoring in the humanities and social sciences, $27.54 \%$ in science and engineering, and $19.92 \%$ in other subjects, including economics and management, medicine and pharmacy, and the arts. Informed consent was obtained from all participants, and ethical approval for research with human subjects was obtained from a committee organized by the Chinese Ministry of Education. Participants were informed of their right to withdraw from the study at any time, the research purpose, and how the researchers would handle their data to ensure confidentiality.

The participants from both universities were Chinese and had studied English for at least six years. As they differed in their English proficiency, all of the questionnaires were prepared in Chinese to ensure they would be accurately understood. In terms of achievement level, the student body in the two universities is recruited from the top 5\% of high school students in the cities in which they sit for the Gaokao, China's national college entrance examination. Every year, nearly 3000 and 4000 students are enrolled in the university in Shanghai and the university in Nanjing, respectively. Most courses at both are delivered in Chinese, although English is the medium of instruction in some. In the past decade, increasing numbers of teachers in China, particularly young teachers, have begun to use teaching methods grounded in the constructivist approach, adopting the methods of group discussion and group or individual projects, encouraging student autonomy, and emphasizing knowledge construction. The teacher-student ratio in the two study universities ranges from 1:10 to $1: 16$.

\section{Measures}

\section{Inventory of Students' Perceived Learning Environment}

ISPLE is grounded in constructivist learning theories. Its eight dimensions derive from the major dimensions described in Entwistle, McCune, and Hounsell's (2003) conceptual model. These dimensions also result from the frequently identified factors in corresponding inventories, such as the Student Engagement Questionnaire (Kember \& Leung, 2009), Experiences of Teaching and Learning Questionnaire (Entwistle et al., 2003), College Student Experience Questionnaire (Pace \& Kuh, 2007), and Inventory of Perceived Study Environment (Wierstra, Kanselaar, Linden, \& Lodewijks, 1999) (for details, see Fan \& Zhang, 2014).

More precisely, ISPLE measures: 1) constructivist-oriented teaching; 2) clear goals and coherence of curricula; 3) student autonomy; 4) assessments and assignments; 5) teacherstudent interaction; 6) student-student cooperation; 7) peer morale and identities; and 8) learning facilities (see definitions and sample items in the appendix). There are 32 items in ISPLE, four items for each dimension. Participants are asked to indicate how accurately each statement describes their perceived learning environment on a 7-point Likert-type scale ranging from 1 (extremely inaccurate) to 7 (extremely accurate).

In the current study, confirmatory factor analysis (CFA) was performed for each of the eight ISPLE dimensions prior to the inventory's use. The CFA results are reported in Table 1. Three items in the subscales of constructivist-oriented teaching, assessments and assignments, and teacher-student interaction, respectively, had very low $R^{2}$ values $(<0.10)$ between the items and corresponding factors. According to Bollen (1989), $R^{2}$ is an indicator of the construct reliability 
of individual items. The higher the $R^{2}$ value, the stronger the item's explanatory power. Therefore, the three aforementioned items were removed, and the composite reliability of the eight ISPLE dimensions then calculated. Two dimensions had a composite reliability value lower than 0.70 , that is, 0.58 for assessments and assignments and 0.65 for teacher-student interaction.

Next, a six-factor ISPLE model (Model 1) was run with these two dimensions removed. In addition, two competing models were constructed for comparison with Model 1, namely, an eight-factor model (Model 2) and a second-order factor model containing six first-order dimensions of ISPLE (Model 3). The results showed that Model 1 fit the data well ${ }^{3}: \chi^{2}{ }_{(212)}=$ $535.149, p<0.001$, root mean square error of approximation $($ RMSEA) $=0.055[0.049,0.060]$, standardized root mean square residual $(\mathrm{SRMR})=0.053$, and comparative fit index $(\mathrm{CFI})=$ 0.913. All items loaded onto their corresponding factors, with factor loading ranging from 0.51 to 0.82 . The error covariances between items 1 and 2 (i.e., "The courses give me a sense of what goes on 'behind the scenes' in the subject areas" and "It is clear to me what I am supposed to learn") and items 7 and 15 (i.e., "The students around me are proactive in learning" and "The students around me always search for further knowledge other than what has been taught in class") were determined to be correlated given the overlap in item content.

Model 2 also fit the data to some extent: $\chi^{2}{ }_{(346)}=908.928, p<0.001$, RMSEA $=0.056[0.052$, $0.061], \mathrm{SRMR}=0.055$, and $\mathrm{CFI}=0.88$. All items loaded onto their corresponding factors, with factor loading ranging from 0.50 to 0.82 . Compared with Model 1, $\Delta$ MLR $\chi_{(134)}^{2}=358.665$ was larger than $\chi_{(134)}^{2}=174.996(\mathrm{p}=0.01)$, indicating that the two models are significantly different and that the six-dimension ISPLE model is more parsimonious and fits the data better $(p<$ 0.01 ). Model 3 was also subsequently tested and found to fit the data: $\chi^{2}{ }_{(221)}=566.555, p<$ $0.001, \mathrm{RMSEA}=0.055[0.050,0.061], \mathrm{SRMR}=0.056$, and CFI $=0.907$. The factor loadings of the first-order six dimensions ranged from 0.75 to 0.95 . The model's $\Delta$ MLR $\chi^{2}{ }_{(9)}=30.686$, which is larger than $\chi_{(9)}^{2}=21.666$ for Model $1(p=0.01)$, indicates that the two models are significantly different and that the six-dimension ISPLE model (Model 1) is more parsimonious and fits the data better than Model $3(p<0.01)$. Based on these results and the $\chi^{2}$ difference tests for the three models, the six-dimension ISPLE model, i.e., Model 1, was selected for use in the following SWB prediction.

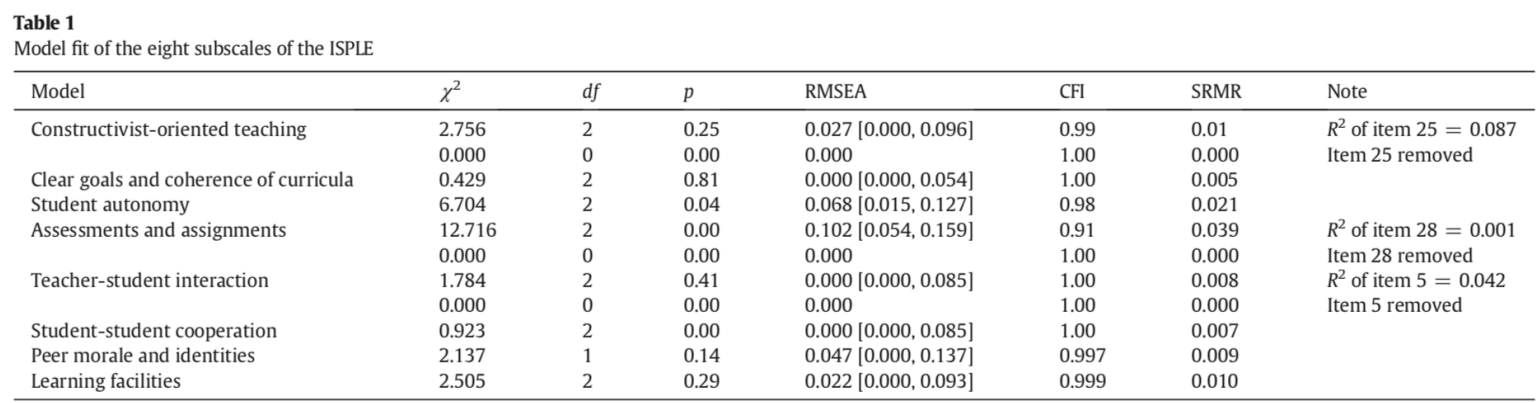

\footnotetext{
${ }^{3}$ Recently, a cutoff of 0.95 rather than the previous 0.90 has been suggested to indicate a good model fit (Hu \& Bentler, 1999; A. Klein \& Moosbrugger, 2000). However, some researchers have pointed out that the "'conventional' rules of thumb about acceptable fit are too restrictive (even though there has been a recent push for even stricter standards)" (Marsh, Hau, \& Wen, 2004, p. 325) and that it is unnecessary to "be overly critical if the CFI is not quite 0.95" (Iacobucci, 2010, p. 95). Accordingly, if the CFI was lower than 0.95 in this study, the SRMR and RMSEA values were simultaneously taken into account in assessing whether there was reasonable model fit.
} 
Student SWB was assessed by two instruments: the Satisfaction with Life Scale (SWLS; Diener, Emmons, Larsen, \& Griffin, 1985) and the Positive and Negative Affect Schedule (PANAS; Watson, Clark, \& Tellegen, 1988). The SWLS contains five items (e.g., "So far, I have achieved important things I want in life") rated on a 7-point Likert-type scale ranging from 1 (not at all true of me) to 7 (exactly true of me), and is widely used to assess life satisfaction, the cognitive component of SWB. The scale has also been used in a wide range of research in non-English speaking territories and countries, including the Palestinian Territories, the Netherlands, Spain, France, and China (e.g., Abdallah, 1998; Arrindell, Heesink, \& Feij, 1999; Atienza, Balaguer, \& García-Merita, 2003; Blais, Vallerand, Pelletier, \& Brière, 1989; Chen, 2015; Ye, 2008).

PANAS (Watson et al., 1988), which assesses the affective component of SWB, is also widely used. It comprises two 10-item subscales, one for positive affect (PA; e.g., "active," "enthusiastic," and "proud") and one for negative affect (NA; e.g., "upset," "nervous," and "afraid"). Participants respond on a 7-point Likert-type scale ranging from 1 (not at all true of me) to 7 (exactly true of me) to indicate their affective experiences in the past month. Satisfactory psychometric properties have been demonstrated in studies in different cultures (e.g., Chen, 2015; Krohne, Egloff, Kohlmann, \& Tausch, 1996; Melvin \& Molloy, 2000; Paradowski, 2001; Ye, 2008).

In the present study, a three-factor CFA model (i.e., life satisfaction and positive and negative affect) was run, with the error covariances of two pairs of items in the NA and PA dimensions set in the prior based on previous results (Ye, 2008). The results indicated that the model fit the data: $\chi_{(270)}^{2}=637.456$, RMSEA $=0.052[0.046,0.057]$, SRMR $=0.049$, and CFI $=0.92$. All items loaded onto their corresponding factors, with factor loadings ranging from 0.42 to 0.91 . Although the model fit indices were acceptable, the modification indices suggested that the errors of two items were correlated (i.e., guilty and ashamed). Accordingly, a modified model was run, and the statistics of model fit were satisfactory: $\chi^{2}{ }_{(269)}=573.265$, RMSEA $=0.047$ $[0.042,0.052]$, SRMR $=0.047$, and CFI $=0.94$. All items loaded onto their corresponding factors, with factor loadings ranging from 0.41 to 0.91 . A corrected $\chi^{2}$ difference test between the original and modified model $\left(\triangle \operatorname{MLR} \chi^{2}{ }_{(1)}=47.964\right.$ versus $\left.\chi_{(1)}^{2}=6.635 ; p=0.01\right)$ indicated that the two models were different and that the modified model fit the data better $(p<0.01)$. The composite reliability of the SWLS and two PANAS subscales were 0.81 (life satisfaction), 0.89 (PA), and 0.90 (NA), respectively.

\begin{tabular}{|c|c|c|c|c|c|c|c|c|c|}
\hline Dimension & 1 & 2 & 3 & 4 & 5 & 6 & 7 & 8 & 9 \\
\hline 1. Life Satisfaction & - & & & & & & & & \\
\hline 2. Positive affect & $0.43^{* * *}$ & - & & & & & & & \\
\hline 3. Negative affect & $-0.35^{* * *}$ & $-0.25^{* * *}$ & - & & & & & & \\
\hline 4. Constructivist-oriented teaching & $0.32^{* * *}$ & $0.38^{* * *}$ & $-0.10^{*}$ & - & & & & & \\
\hline 5. Clear goals and coherence of curricula & $0.33^{* * * *}$ & $0.37^{* * * *}$ & $-0.15^{* *}$ & $0.63^{* * *}$ & - & & & & \\
\hline 6. Student autonomy & $0.20^{* * *}$ & $0.32^{* * *}$ & -0.05 & $0.59^{* * *}$ & $0.51^{* * *}$ & - & & & \\
\hline 7. Student-student cooperation & $0.36^{* * *}$ & $0.39^{* * * *}$ & -0.05 & $0.55^{* * * *}$ & $0.49^{* * * *}$ & $0.50^{* * * *}$ & - & & \\
\hline 8. Peer morale and identities & $0.26^{* * *}$ & $0.36^{* * *}$ & 0.01 & $0.55^{* * *}$ & $0.48^{* * * *}$ & $0.46^{* * *}$ & $0.58^{* * * *}$ & - & \\
\hline 9. Learning facilities & $0.33^{* * *}$ & $0.41^{* * *}$ & -0.03 & $0.56^{* * *}$ & $0.42^{* * *}$ & $0.44^{* * *}$ & $0.48^{* * *}$ & $0.59^{* * *}$ & - \\
\hline M & 4.86 & 4.35 & 3.01 & 4.85 & 4.27 & 4.45 & 4.71 & 4.77 & 5.62 \\
\hline$S D$ & 1.03 & 1.02 & 1.11 & 1.14 & 1.06 & 1.10 & 1.08 & 1.19 & 1.19 \\
\hline Composite reliability & 0.81 & 0.89 & 0.90 & 0.71 & 0.73 & 0.70 & 0.78 & 0.79 & 0.82 \\
\hline
\end{tabular}




\section{Procedures and data analyses}

The participating students completed the questionnaires and provided demographic information (i.e., sex, major, and year) in class. Completed questionnaires were collected by the researchers on the day they were administered. Correlation analysis was performed to determine the relations between perceived CLE and the SWB dimensions. CFA and latent variable modeling were carried out using Mplus 7 (Muthén \& Muthén, 1998-2012) to examine the psychometric properties of the measures and the association between perceived CLE and SWB. The robust maximum likelihood (MLR) estimator was used in the analysis to avoid a multivariate nonnormal distribution and to compute valid values. Compared with the default ML estimator, MLR is robust to non-normality (Muthén \& Muthén, 1998-2012). Regardless of whether the distribution of observed variables is univariate normal, the multivariate distribution can still be multivariate non-normal (West, Finch, \& Curran, 1995, cited in Byrne, 2012). As a result, a corrected chi-square difference test was performed to confirm whether the difference in model fit between the two models was significant (Byrne, 2012).

\section{Results}

\section{Preliminary data analyses}

The mean, SD, and composite reliability of perceived CLE and SWB are presented in Table 2. According to Byrne's (1998) standard ${ }^{4}$, all key variable dimensions were univariate normal. Table 2 also reports the intercorrelations among perceived CLE and the SWB dimensions. As can be seen, the six CLE dimensions were found to be significantly and positively correlated with life satisfaction and PA (all $p$ s $<0.001$ ), with correlation coefficients ranging from 0.20 to 0.41 , and the CLE dimensions of clear goals and coherence of curricula $(r=-0.15)$ and constructivist-oriented teaching $(r=-0.10)$ to be negatively related to NA (all $p \mathrm{~s}<0.05)$. Life satisfaction was positively and negatively associated with PA $(r=0.43)$ and NA $(r=-0.35)$, respectively, and PA and NA ( $r=-0.25)$ were negatively correlated with each other (all $p \mathrm{~s}<$ $0.001)$. The eight CLE dimensions were positively correlated with one another, with correlation coefficients ranging from 0.32 to 0.63 (all $p \mathrm{~s}<0.001$ ).

\section{Link between CLE dimensions and student SWB}

Latent variable modeling was performed to examine the relationship between perceived CLE and student SWB, with perceived CLE comprising six dimensions (i.e., constructivist-oriented teaching; clear goals and coherence of curricula; student autonomy; student-student cooperation; peer morale and identities; and learning facilities) and SWB comprising life satisfaction and PA and NA. To determine how perceived CLE is related to student SWB, several demographic variables, including age, sex $(0=$ male, $1=$ female $)$, university $(0$ and 1 representing the Nanjing and Shanghai universities, respectively), and major, were controlled. ${ }^{5}$

The statistics of the model test were: $\chi_{(1263)}^{2}=2538.086, p<0.001$, RMSEA $=0.044$ [0.042, 0.047], $\mathrm{SRMR}=0.061$, and CFI $=0.88$. With regard to the effects of demographic variables, sex alone was found to influence life satisfaction $(\beta=0.11, p=0.035), \mathrm{PA}(\beta=-0.10, p=$ $0.041)$, and NA $(\beta=-0.12, p=0.024)$. In other words, female students reported a higher level

\footnotetext{
${ }^{4}$ Variables with absolute values of skewness and kurtosis below 2.00 and 7.00, respectively, are regarded as normally distributed (Byrne, 1998).

${ }^{5}$ Two dummy variables were created for major given that the variable has three categories $(1=$ humanities and social sciences, 2 = science and engineering, and 3 = others; the category of other subjects was used as the reference group).
} 
of life satisfaction, but lower levels of positive and negative affect, than male students. Based on the parsimony principle, all other demographic variables were removed from the model, with the trimmed model then run and shown to fit the data well: $\chi_{(1083)}^{2}=2036.207, p<0.001$, RMSEA $=0.041[0.039,0.044]$, SRMR $=0.053$, and CFI $=0.90$.

The model results showed that clear goals and coherence of curricula was positively related to life satisfaction $(\beta=0.38, p=0.009)$ and PA $(\beta=0.29, p=0.017)$, and negatively related to NA ( $\beta=-0.25, p=0.059)$ to a marginal degree. In addition, learning facilities was positively linked to life satisfaction $(\beta=0.24, p=0.038)$ and PA $(\beta=0.28, p=0.005)$. Student-student cooperation $(\beta=0.55, p=0.006)$ was positively associated with life satisfaction, whereas student autonomy $(\beta=-0.32, p=0.008)$ was negatively associated with it. Sex appeared to be link to life satisfaction $(\beta=0.10, p=0.023)$, PA $(\beta=-0.11, p=0.009)$, and NA $(\beta=-0.13, p$ $=0.007)$. Finally, the four aforementioned CLE dimensions were found to be positively correlated with one another, with coefficients ranging from 0.54 to 0.70 (all $p \mathrm{~s}<0.001$ ). The path diagram is presented in Fig. 1.

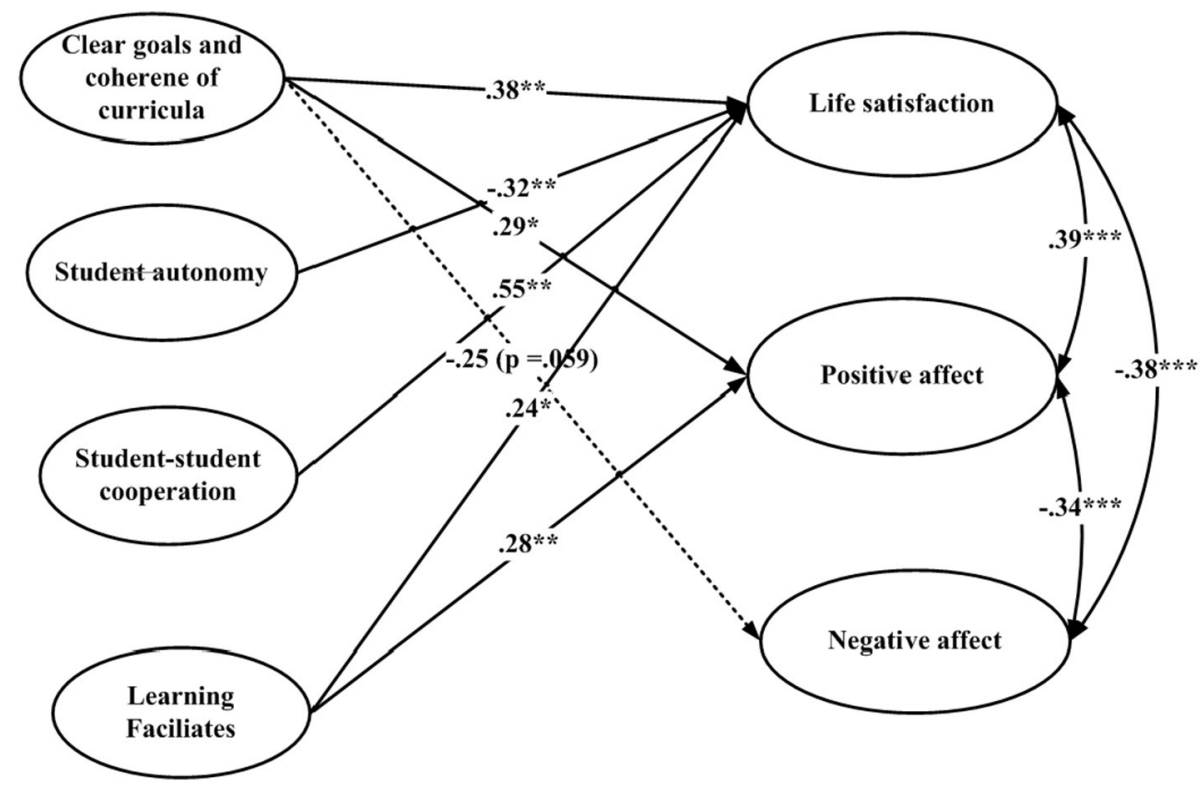

Fig. 1. The path diagram of the relationship between perceived learning environment and subjective well-being. Note. For brevity and clearance, the correlations among the four dimensions of constructivist learning environment were not presented. $* * * p<0.001 * * p<0.01 * p<0.05$.

\section{Discussion}

The effectiveness of CLE has been debated for years. One reason for the ongoing debate is the differing nature of the assessments used to evaluate learning outcomes in previous studies (Schwartz, Lindgren, \& Lewis, 2009). The present study, by examining the relationship between multiple CLE dimensions and SWB in university students, suggests that non-academic outcomes could be a promising way to provide additional insights for the discussion of CLE effectiveness. Although no specific hypotheses were proposed with respect to how different CLE dimensions would be related to SWB, the findings suggest that, generally speaking, the more constructivist in nature students perceive the learning environment to be, the higher their SWB. 
Two potential reasons may explain why CLE is associated with students' SWB. First, as noted in the introduction, CLE may help students to engage in the learning process and identify the meaning of tasks.

Engagement and meaningfulness are two dimensions relevant to wellbeing (Cohen, 2006). Second, multiple aspects of CLE may be more likely to meet students' diverse needs and learning demands. For example, some students may focus on how teachers deliver knowledge, organize classes, and evaluate students, some may value peer interaction, such as peer support and collaboration, and some may be more interested in the learning facilities and resources that the university provides. In this study, the learning environment considered included dimensions inside and outside the classroom. Indeed, in addition to the teaching and learning activities occurring in the classroom, student cooperation, peer morale, and on-campus learning facilities (e.g., libraries, self-study space, seminars, and internship opportunities) were also measured. In this sense, students whose diverse needs and requirements for knowledge acquisition and development were met were more likely to be satisfied with their lives and have positive affect. Of course, additional data from future studies are needed to confirm our interpretations.

The present study found specific CLE dimensions, namely, those related to teachers (i.e., clear goals and coherence of curricula), peers (i.e., student-student cooperation), and learning facilities, to be linked to higher levels of SWB. These results echo previous research findings showing certain CLE dimensions (e.g., classmate relationships, teacher-student relationships, teacher and peer support, and collaborative learning) to be positively associated with students' domain satisfaction (Baker, 1998, 1999; Gest et al., 2005; Kangas, 2010; Maton, 1990; Shernoff et al., 2003; So \& Brush, 2008; Tan \& Zeng, 2007).

The main tasks for university students are learning and development. Therefore, if teachers make course goals clear and plan curricula in a way that matches those goals, students will be more likely to understand exactly what they are supposed to learn, and prepare themselves for learning. Clear goals and learning preparedness may help them to master course content, decrease the extent of unknowns and increase their sense of control, which may in turn enhance their life satisfaction and PA while decreasing their NA. In addition, learning does not take place only in class and only between teachers and students. Sufficient facilities that support constructivist learning might also be important for students' SWB. If students have sufficient learning-conducive equipment and academic resources on campus (e.g., good places to study, plenty of materials other than textbooks in the library, numerous lectures and seminars beyond their courses, and a wide range of extracurricular activities and/or internship opportunities), there is little doubt that they will feel satisfied with their university life and learning environment, and thus experience more positive emotions and feelings.

At the same time, university students are at a stage of development in which peers play a particularly important role. Students work with their peers, exchange information, observe one another's behavior, and instigate and maintain engagement with one another in various academic activities. Therefore, if students are encouraged to communicate and work with one another in their courses, they will have more opportunities to discuss course ideas with their fellow students, get help when they encounter difficulties, and achieve a better understanding of the learning materials. Moreover, student-student cooperation may not only be conducive to learning, but also help students to overcome emotional problems and find strategies for dealing with unhappiness. It is possible that such cooperation plays a positive role in students' life satisfaction at the university.

Nonetheless, it should be noted that a negative relationship between student autonomy and life satisfaction appeared in our data. Such a result is inconsistent with previous studies showing satisfaction with courses and fellow students to be positively associated with learning 
environments that permit student autonomy and engagement (Kangas, 2010; Maton, 1990; Shernoff et al., 2003). However, it might not be particularly surprising in the Chinese context. The participants in this study were all in their freshman or sophomore year of university, and had thus graduated from high school relatively recently. In Chinese high schools, teachers generally deliver knowledge and skills to students in the classroom, which students passively receive with little freedom to question. As a result, students are generally more concerned with their academic performance and less with whether their opinions and ideas about teaching and learning are taken into account by their teachers. In other words, high school students are accustomed to a unidirectional teaching and learning process. Thus, when they first enter university, they may feel uncomfortable when presented with opportunities to exercise choice and initiative. In fact, if afforded too much freedom and too many choices, students may even feel dissatisfied with their teachers and classes. Both the negative relation between perceived student autonomy and life satisfaction in a Chinese context and our interpretation of it require further investigation to reach a firm conclusion.

\section{Contributions, limitations, and implications for education}

The main contribution of this study is its addition of new elements to the debate on CLE effectiveness. Even if these results are correlational, they supported a relationship between this type of learning environment and university students' well-being. Moreover, the study has also validated an inventory for assessing the general CLE (i.e., ISPLE) in a Chinese context, although there is room for further improvement. Despite the popularity of constructivism, empirical research systematically examining the adoption of CLE remains far from sufficient (Tobias, 2009) and the ISPLE may be a useful tool in facilitating future research in this regard.

Despite its contributions, this study also had several limitations. First, it featured a retrospective rather than longitudinal research design. Hence, its results are only correlational in nature, and no causal conclusions can be drawn. Although it may be tempting to claim that CLE influences student SWB, alternative explanations cannot be ruled out based on our data. For example, it is possible that the students who reported higher SWB may also have perceived their environment as more oriented toward constructivism. Therefore, longitudinal studies in which students' initial SWB is controlled or experimental studies in which features of constructivist learning environments are manipulated are essential to identify if CLE influences students' SWB. Second, the study assessed only student perceptions of CLE, and the CLE data are thus subjective. A fruitful direction for future research would be to collect data from teachers' reports and researchers' observations to complement the student perspective, thereby obtaining a more accurate view of CLE's influence on SWB (through triangulation). Third, and finally, some of the ISPLE items may have been confounded with participants' personality characteristics. For example, responses to the item "I frequently discuss ideas from courses with other students" in student-student cooperation could reflect extraversion. Similarly, responses concerning the available learning facilities could be influenced by conscientiousness, with conscientious student more active in seeking out such facilities. Hence, future research should consider students' personality characteristics to obtain a better understanding of the CLE-SWB link.

Notwithstanding these limitations, this study provides useful information for educators, practitioners, and researchers alike, suggesting the need for them to consider multiple aspects of the constructivist learning environment in examining its effectiveness. Moreover, by confirming the link between learning environment and students' SWB, these results also highlight that education is not just a matter of performance and others factors deserve our attention as well. 


\section{Acknowledgments}

This project was supported by the Humanities and Social Sciences Research Grant financed by Ministry of Education of People's Republic of China (No. 10YJCXLX002), the 12th Five-Year Plan Research Grant of Jiangsu Education Science (No. B-b/2011/01/023), and the Philosophy and Social Sciences Research Grant financed by Jiangsu Education Department (No. 2010SJBXLX004).

\section{References}

Abdallah, T. (1998). The Satisfaction with Life Scale (SWLS): Psychometric properties in an Arabic-speaking sample. International Journal of Adolescence \& Youth, 7(2), 113-119.

Albanese, M. A., \& Mitchell, S. (1993). Problem-based learning: A review of literature on its outcomes and implementation issues. Academic Medicine, 68(1), 52-81.

Arrindell, W. A., Heesink, J., \& Feij, J. A. (1999). The Satisfaction with Life Scale (SWLS): Appraisal with 1700 health young adults in the Netherlands. Personality and Individual Differences, 26(5), 815-826.

Atienza, F. L., Balaguer, I., \& García-Merita, M. L. (2003). Satisfaction with Life Scale: Analysis of factorial invariance across sexes. Personality and Individual Differences, 35(6), 1255-1260.

Baker, J. A. (1998). The social context of school satisfaction among urban, low-income, African-American students. School Psychology Quarterly, 13(1), 25-44.

Baker, J. A. (1999). Teacher-student interaction in urban at-risk classrooms: Differential behavior, relationship quality, and student satisfaction with school. The Elementary School Journal, 100(1), 57-70.

Blais, M. R., Vallerand, R. J., Pelletier, L. G., \& Brière, N. M. (1989). The satisfaction scale: Canadian-French validation of the Satisfaction with Life Scale. Canadian Journal of Behavioural Science, 21(2), 210-223.

Bollen, K. A. (1989). Structural equations with latent variables. New York: Wiley.

Brooks, J. G., \& Brooks, M. G. (1993). In search of understanding: The case for constructivist classrooms. Alexandria VA: Association for Supervision and Curriculum Development.

Byrne, B. M. (1998). Structural equation modeling with LISREL, PRELIS, and SIMPLIS: Basic concepts, application, and programming. Mahwah, N.J.: L. Erlbaum Associates.

Byrne, B. M. (2012). Structural equation modeling with Mplus: Basic concepts, applications, and programming. New York, NY: Taylor \& Francis Group.

Chen, C. (2015). Incremental validity of achievement goals in predicting subjective wellbeing among university students. Journal of Cognitive Education and Psychology, 14(1), 38-62.

Cohen, J. (2006). Social, emotional, ethical, and academic education: Creating a climate for learning, participation in democracy, and well-being. Harvard Educational Review, 76(2), 201-237.

De Corte, E. (1995). Fostering cognitive growth: A perspective from research on methemetics learning and instruction. Educational Psychologist, 30(1), 37-46.

De Corte, E. (2000). Marrying theory building and the improvement of school practice: A permanent challenge for instructional psychology. Learning and Instruction, 10(3), 249-266.

Dethlefs, T. M. (2003). Relationship of constructivist learning environment to student attitudes and achievement in high school mathematics and science. Dissertation Abstracts International Section A: Humanities and Social Sciences, 63(7-A), 2455.

Diener, E. (1984). Subjective well-being. Psychological Bulletin, 95(3), 542-575.

Diener, E., \& Biswas-Diener, R. (2002). Will money increase subjective well-being? Social Indicators Research, 57(2), 119-169.

Diener, M. L., \& Diener McGavran, M. B. (2008). What makes people happy? A developmental approach to the literature on family relationships and well-being. In M. Eid, \& R. J. Larsen (Eds.), The science of subjective wellbeing (pp. 347-375). New York, NY, US: Guilford Press. 
Diener, E., Tay, L., \& Oishi, S. (2013). Rising income and the subjective well-being of nations. Journal of Personality \& Social Psychology, 104(2), 267-276.

Diener, E., Emmons, R. A., Larsen, R. J., \& Griffin, S. (1985). The Satisfaction with Life Scale. Journal of Personality Assessment, 49(1), 71-75.

Diener, E., Lucas, R. E., Oishi, S., \& Suh, E. M. (2002). Looking up and down: Weighting good and bad information in life satisfaction judgments. Personality and Social Psychology Bulletin, 28(4), 437-445.

Diener, E., Oishi, S., \& Lucas, R. E. (2009). Subjective well-being: The science of happiness and life satisfaction. In C. R. Snyder, \& S. J. Lopez (Eds.), Oxford handbook of positive psychology (pp. 187-194) (2nd ed.). Oxford, New York: Oxford University Press.

Dinsmore, D. L., Alexander, P. A., \& Loughlin, S. M. (2008). The impact of new learning environments in an engineering design course. Instructional Science, 36(5-6), 375-393.

Dyrbye, L. N., Thomas, M. R., Harper, W., Massie, F. S., Power, D. V., Eacker, A., ... Shanafelt, T. D. (2009). The learning environment and medical student burnout: A multicentre study. Medical Education, 43(3), $274-282$.

Entwistle, N., McCune, V., \& Hounsell, J. (2003). Investigating ways of enhancing university teaching-learning environments: Measuring students' approaches to studying and perceptions of teaching. In E. de Corte, L. Verschaffel, N. Entwistle, \& J. Van Merriënboer (Eds.), Powerful learning environments: Unravelling basic components and dimensions (pp. 89-107). Oxford, England: Pergamon/Elsevier Science Ltd.

Fan, J., \& Zhang, L. F. (2014). The role of learning environments in thinking styles. Educational Psychology, 34(2), 252-268.

Fraser, B. J. (1998). The birth of a new journal: Editor's introduction. Learning Environments Research, 1(1), 15 .

Gest, S. D., Welsh, J. A., \& Domitrovich, C. E. (2005). Behavioral predictors of changes in social relatedness and liking school in elementary school. Journal of School Psychology, 43(4), 281-301.

Harris, K. R., Santangelo, T., \& Graham, S. (2008). Self-regulated strategy development in writing: Going beyond NLEs to a more balanced approach. Instructional Science, 36(5-6), 395-408.

Hu, L. T., \& Bentler, P. M. (1999). Cutoff criteria for fit indexes in covariance structure analysis: Conventional criteria versus new alternatives. Structural Equation Modeling: A Multidisciplinary Journal, 6(1), 1-55.

Huang, S. Y. L., \& Fraser, B. J. (2009). Science teachers' perceptions of the school environment: Gender differences. Journal of Research in Science Teaching, 46(4), 404-420.

Iacobucci, D. (2010). Structural equations modeling: Fit indices, sample size, and advanced topics. Journal of Consumer Psychology, 20(1), 90-98.

Iyer, A., Jetten, J., Tsivrikos, D., Postmes, T., \& Haslam, S. A. (2009). The more (and the more compatible) the merrier: Multiple group memberships and identity compatibility as predictors of adjustment after life transitions. British Journal of Social Psychology, 48(4), 707-733.

Johnson, V. E. (1997). An alternative to traditional GPA for evaluating student performance. Statistical Science, 12(4), 251-278.

Kangas, M. (2010). Finnish children's views on the ideal school and learning environment. Learning Environments Research, 13(3), 205-223.

Kember, D., \& Leung, D. Y. P. (2009). Development of a questionnaire for assessing students' perceptions of the teaching and learning environment and its use in quality assurance. Learning Environments Research, 12(1), 1529.

Klein, A., \& Moosbrugger, H. (2000). Maximum likelihood estimation of latent interaction effects with the LMS method. Psychometrika, 65(4), 457-474.

Klein, J. D., \& Schnackenberg, H. L. (2000). Effects of informal cooperative learning and the affiliation motive on achievement, attitude, and student interactions. Contemporary Educational Psychology, 25(3), 332-341.

Krohne, H. W., Egloff, B., Kohlmann, C. -W., \& Tausch, A. (1996). Investigations with a German version of the Positive and Negative Affect Schedule (PANAS). Diagnostica, 42(2), 139-156.

Kumar, R., O'Malley, P. M., \& Johnston, L. D. (2008). Association between physical environment of secondary schools and student problem behavior: A national study, 2000-2003. Environment and Behavior, 40(4), 455-486. 
Li, K., Hu, B. Y., Pan, Y., Qin, J., \& Fan, X. (2014). Chinese Early Childhood Environment Rating Scale (trial) (CECERS): A validity study. Early Child Research Quarterly, 29(3), 268-282.

Loyens, S. M. M., \& Gijbels, D. (2008). Understanding the effects of constructivist learning environments: Introducing a multi-directional approach. Instructional Science, 36(5-6), 351-357.

Loyens, S. M. M., Rikers, R. M. J. P., \& Schmidt, H. G. (2007). The impact of students' conceptions of constructivist assumptions on academic achievement and drop-out. Studies in Higher Education, 32(5), 581-602.

Lucas, R. E. (2005). Time does not heal all wounds: A longitudinal study of reaction and adaptation to divorce. Psychological Science, 16(12), 945-950.

Lucas, R. E., Clark, A. E., Georgellis, Y., \& Diener, E. (2004). Unemployment alters the set point for life satisfaction. Psychological Science, 15(1), 8-13.

Marsh, H. W., Hau, K. -T., \& Wen, Z. (2004). In search of golden rules: Comment on hypothesis-testing approaches to setting cutoff values for fit indexes and dangers in overgeneralizing $\mathrm{Hu}$ and Bentler's (1999) findings. Structural Equation Modeling: A Multidisciplinary Journal, 11(3), 320-341.

Mason, L. H. (2004). Explict self-regulated strategy development versus reciprocal questioning: Effects on expository reading comprehension among struggling readers. Journal of Educational Psychology, 96(2), $283-296$.

Maton, K. I. (1990). Meaningful involvement in instrumental activity and well-being: Studies of older adolescents and at risk urban teen-agers. American Journal of Community Psychology, 18(2), 297-320.

Melvin, G., \& Molloy, G. N. (2000). Some psychometric properties of the Positive and Negative Affect Schedule among Australian youth. Psychological Reports, 86(3), 1209-1212.

Milkie, M. A., \& Warner, C. H. (2011). Classroom learning environments and the mental health of first grade children. Journal of Health and Social Behavior, 52(1), 4-22.

Moreno, R., \& Mayer, R. E. (1999). Multimedia-supported metaphors for meaning making in mathematics. Cognition and Instruction, 17(3), 215-248.

Muthén, L. K., \& Muthén, B. O. (1998-2012). Mplus user's guide (7th ed.). Los Angeles, CA: Muthén \& Muthén. Noddings, N. (2005). Happiness and education Cambridge. UK: Cambridge University Press.

Oishi, S. (2001). Culture and memory for emotional experiences: On-line vs. retrospective judgments of subjective well-being. Dissertation Abstracts International: Section B: The Sciences and Engineering, 61(10-B), 5625.

Pace, C. R. and Kuh, G. D. (2007). The college student experiences questionnaire assessment program. from http://cseq.iub.edu/cseq_generalinfo.cfm

Paradowski, J. H. (2001). Positive affectivity, negative affectivity, and job satisfaction: A meta-analysis. Dissertation Abstracts International: Section B: The Sciences and Engineering, 61(12-B), 6749.

Paykel, E. S. (2003). Life events and affective disorders. Acta Psychiatrica Scandinavica, 108, 61-66.

Poropat, A. E. (2009). A meta-analysis of the Big Five Model of personality and academic performance. Psychological Bulletin, 135(2), 322-338.

Rutter, M., \& Maughan, B. (2002). School effectiveness findings, 1979-2002. Journal of School Psychology, $40(6), 451-475$.

Schwartz, D. L., Lindgren, R., \& Lewis, S. (2009). Constructivist in an age of non-constructivist assessments. In S. Tobias, \& T. M. Duffy (Eds.), Constructivist instruction: Success or failure. New York: Routledge.

Shernoff, D. J., Csikszentmihalyi, M., Shneider, B., \& Shernoff, E. S. (2003). Student engagement in high school classrooms from the perspective of flow theory. School Psychology Quarterly, 18(2), 158-176.

So, H. -J., \& Brush, T. A. (2008). Student perceptions of collaborative learning, social presence and satisfaction in a blended learning environment: Relationships and critical factors. Computers \& Education, 51(1), 318-336.

Steffe, L. P., \& Gale, J. E. (1995). Constructivism in education. Hillsdale, N.J.: Lawrence Erlbaum.

Suldo, S. M., McMahan, M. M., Chappel, A. M., \& Loker, T. (2012). Relationships between perceived school climate and adolescent mental health across genders. School Mental Health, 4(2), 69-80.

Tan, Q. -B., \& Zeng, M. (2007). Class environment and life satisfaction of 548 high school students. Chinese Mental Health Journal, 21(8), 544-547. 
Tobias, S. (2009). An eclectic appraisal of the success or failure of constructivist instruction. In S. Tobias, \& T. M. Duffy (Eds.), Constructivist instruction: Success or failure (pp. 335-350). New York and London: Routledge.

Thompson, E. R. (2007). Development and validation of an internationally reliable shortform of the Positive and Negative Affect Schedule (PANAS). Journal of Cross-Cultural Psychology, 38(2), 227-242.

van Merriënboer, J. J. G., \& Paas, F. (2003). Powerful learning and the many faces of in structional design: Toward a framework for the design of powerful learning environments. In E. D. Corte, L. Verschaffel, N. Entwistle, \& J. J. G. van Merriënboer (Eds.), Powerful learning environments: Unravelling basic components and dimensions (pp. 3-20). Oxford, UK: Elsevier Science.

Veenhoven, R., Ehrhardt, J., Ho, M. S. D., \& de Vries, A. (1993). Happiness in nations: Subjective appreciation of life in 56 nations 1946-1992. Rotterdam, Netherlands: Erasmus University Rotterdam.

Vermunt, J. D. (2003). The power of learning environments and the quality of student learning. In E. D. Corte, L. Verschaffel, N. Entwistle, \& J. J. G. van Merriënboer (Eds.), Powerful learning environments: Unravelling basic components and dimensions (pp. 109-124). Oxford, UK: Elsevier Science.

Watson, D., Clark, L. A., \& Tellegen, A. (1988). Development and validation of brief measures of positive and negative affect: The PANAS scales. Journal of Personality and Social Psychology, 54(6), 1063-1070.

Weinberger, E., \& McCombs, B. L. (2001). The impact of learner-centered practices on the academic and nonacademic outcomes of upper elementary and middle school students. (Paper presented at the The Annual Convention of the American Educational Research Association, Seattle).

West, S. G., Finch, J. E., \& Curran, P. J. (1995). Structural equation models with non-normal variables: Problems and remedies. In R. H. Hoyle (Ed.), Structural equation modeling: Concepts, issues, and applications (pp. 56-75). CA: Sage: Thousand Oaks.

Wierstra, R. F. A., Kanselaar, G., Linden, J. L. V. D., \& Lodewijks, H. G. L. C. (1999). Learning environment perceptions of european university students. Learning Environments Research, 2(1), 79-98.

Ye, S. (2008). A longitudinal study of subjective well-being among Chinese university students: the roles of personality, attribution, and coping. Pokfulam, Hong Kong: The University of Hong Kong.

How to cite:

Chen, C., Fan, J., \& Jury, M. (2017). Are perceived learning environments related to subjective well-being? A visit to university students. Learning and Individual Differences, 54, 226-233. doi: 10.1016/j.lindif.2017.01.001 